\title{
触 New Disease Reports \\ Fomitopsis sp. causing brown rot in wood of living citrus trees reported for first time in southern Italy
}

A. Roccotelli ${ }^{1,2}$, L. Schena ${ }^{1}$, S.M. Sanzani ${ }^{2}$, S.O. Cacciola ${ }^{3}$ and A. Ippolito ${ }^{2 *}$

${ }^{1}$ Dipartimento di Gestione dei Sistemi Agrari e Forestali, Università degli Studi Mediterranea, Località Feo di Vito, 89122 Reggio Calabria, Italy; ${ }^{2}$ Dipartimento di Protezione delle Piante e Microbiologia Applicata, Università degli Studi Aldo Moro, Via Amendola 165/A, 70126 Bari, Italy; ${ }^{3}$ Dipartimento di Chimica biologica, Chimica medica e Biologia molecolare, Università degli Studi, Viale Andrea 6, 95125 Catania, Italy

*E-mail: ippolito@agr.uniba.it

Received: 21 Apr 2010. Published: 14 Sep 2010. Keywords: wood rot, Citrus sinensis, Citrus limon, Citrus aurantium, ITS regions

In the spring of 2008 a brown wood rot in 40-year-old orange trees (Citrus sinensis cv. Valencia late) was observed in an orchard in the province of Taranto , Apulia region, Southern Italy . Affected trees (about 20\%), showed symptoms of leafchlorosis, twig dieback and branch breakdown. In the incipient stage of decay the wood showed a yellow-brown discoloration (Fig. 1), which progressed into a wood rot. The fungal mycelium, consistently isolated from decaying wood on potato dextrose agar (PDA), was white, slow growing, slightly raised and cottony-floccose (Fig. 2), with a distinct mushroom odour; hyphae were hyaline, thin-walled, nodose-septate and branched. Representative isolates had identical internal transcribed spacer (ITS) regions (GenBank Accession Nos. HM126455 to HM126460) and were identified as Fomitopsis sp. since their sequences showed $99-100 \%$ identity with available sequences in GenBank.

Pathogenicity of six representative isolates of Fomitopsis sp. was evaluated on twelve 30-year-old trees of lemon (Citrus limon cv. Femminello) (two trees per each isolate) and six of sour orange (Citrus aurantium) (one tree per each isolate). The inoculum consisted of sterilised wheat grains on which Fomitopsis sp. was grown for 20 days at $24^{\circ} \mathrm{C}$. Isolates were inoculated on trees by inserting five wheat grains in $1.5 \mathrm{~cm}$ deep holes which were covered with wet gauze and mastic. Three branches were inoculated for each tree, while one branch, inoculated with five sterile grains, served as a control. Brown discoloration of the wood and a crumbly rot extending 4-5 cm above and below from the inoculation hole were clearly observed eight months later in lengthwise sections of inoculated branches of lemon trees (Fig. 3). Less evident symptoms were also observed in sour orange wood, while control branches remained healthy. The causal agent was re-isolated and Koch's postulates were confirmed.

Fomitopsis spp. commonly attack both conifers and hardwoods (Ryvarden \& Gilbertson, 1993), but also apple, pear, plum, cherry, and peach(Adaskaveg et al., 1993). However, to our knowledge, this is the first report of Fomitopsis sp. causing disease on citrus.Sun-burning of branches and large wounds after heavy pruning, through which the pathogen gained entrance, could have been predisposing factors to such severe infections. The pathogen may represent a threat for bearing citrus orchards and surrounding woody plants since no control measure are available.

\section{References}

Adaskaveg JE, Miller RW, Gilbertson RL, 1993. Wood decay, lignicolous fungi, and decline of peach trees in South Carolina. Plant Disease 77, 707-711.

Ryvarden L, Gilbertson RL, 1993. European polypores. Vol. 1. Oslo, Norway: Fungiflora.

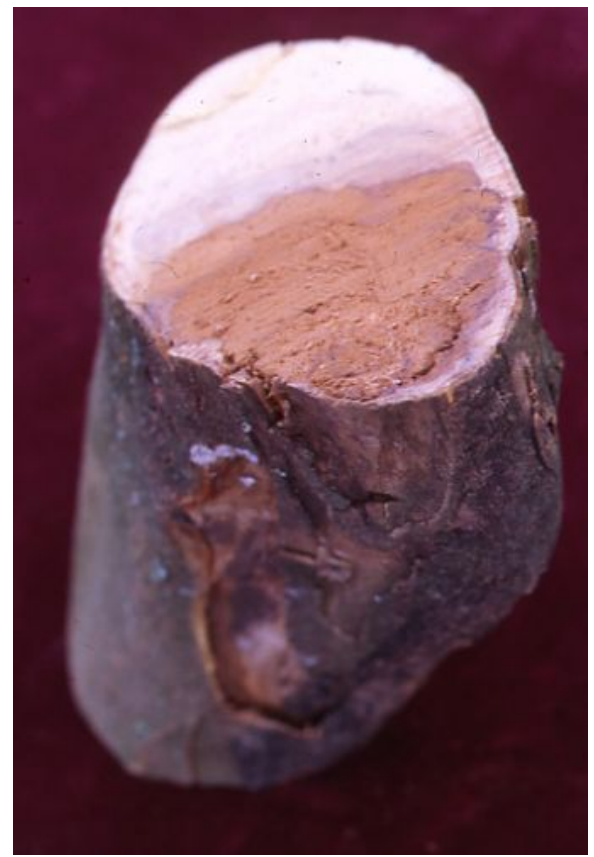

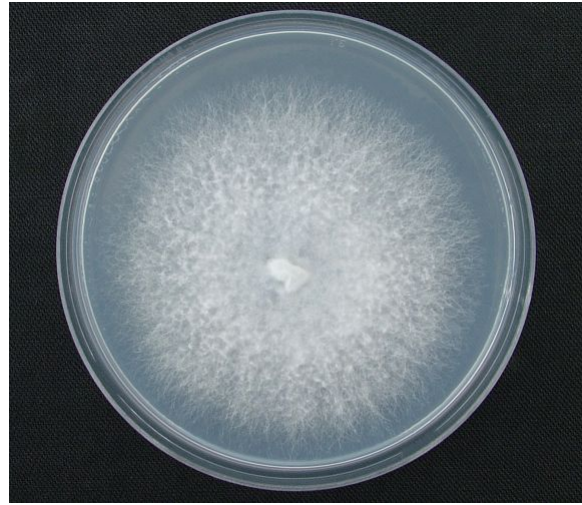

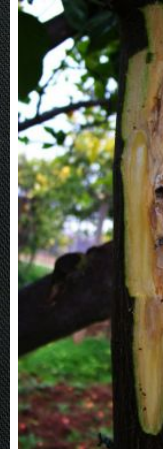

Figure 3 